April 2011

\title{
MARO as the Partial Operationalization of R2P
}

Maureen S. Hiebert

Follow this and additional works at: https://digitalcommons.usf.edu/gsp

\section{Recommended Citation}

Hiebert, Maureen S. (2011) "MARO as the Partial Operationalization of R2P," Genocide Studies and Prevention: An International Journal: Vol. 6: Iss. 1: Article 7.

Available at: https://digitalcommons.usf.edu/gsp/vol6/iss1/7

This Articles is brought to you for free and open access by the Open Access Journals at Digital Commons @ University of South Florida. It has been accepted for inclusion in Genocide Studies and Prevention: An International Journal by an authorized editor of Digital Commons @ University of South Florida. For more information, please contact digitalcommons@usf.edu. 


\title{
MARO as the Partial Operationalization of R2P
}

\author{
Maureen S. Hiebert \\ University of Calgary
}

\section{Introduction}

The authors of MARO: Mass Atrocity Response Operations; A Military Planning Handbook, Sarah Sewall, Dwight Raymond, and Sally Chin, emphasize more than once in their proposed manual that while MARO is not currently US military doctrine "it should be." Clearly favoring the idea that the US military should be prepared to carry out missions other than traditional warfare and counter-terrorism, MARO's authors give us a reasonably solid first crack at how military force might be profitably used to deter and stop genocide and other atrocities. Although the authors contend, correctly, that the MARO project is different from many elements of the Responsibility to Protect (R2P) doctrine, the rationale for and content of the handbook are in fact grounded firmly in R2P's overarching principle of protecting populations at risk of serious harm. It is more accurate to say that $M A R O$, while not the operationalization of all of the R2P doctrine, is the operationalization of one specific aspect of R2P: the responsibility to react through military intervention.

While the step from principle to planning is an important and worthwhile exercise, we should not assume that this step will necessarily lead to effective intervention when the world is confronted with mass atrocities in the future. Instead, $M A R O$ simply offers a preliminary blueprint for how the United States and other would-be coalition forces could carry out different kinds of humanitarian missions to stop or deter atrocity crimes should they be asked to do so by their political masters. And the latter, of course, is the rub. Without the political will to live up to their international responsibility to protect, the United States and other governments will not assign to their armed forces the mission of saving lives in distant places, thus leaving the prospects for effective intervention and prevention as uncertain as ever. In the most optimistic but unlikely scenario, the adoption of the MARO project or something like it into US military doctrine might serve to embolden political leaders to sanction humanitarian military missions. With a plan in the drawer, so to speak, political leaders might feel more confident that they can use military force to protect vulnerable populations since they would have a set of options for how to use that force effectively available to them from the start. Having this capability may in turn reduce the fear of failure or of being drawn into a humanitarian quagmire.

Whether or not MARO will become US military doctrine or serve to deter and stop atrocities, the handbook is worthy of serious consideration. The present commentary will begin by briefly suggesting that $M A R O$ is the operationalization of some of the principles underpinning military intervention formulated in the R2P doctrine and then discuss the degree to which Sewall, Raymond, and Chin have succeeded in this task. On the positive side, they have produced a nuanced document that takes into consideration many of the complexities of mass atrocity crises includ- 
ing the differing and at times competing roles of the various actors involved in such crises and their possible resolution, the complexity of different kinds of humanitarian military operations, the possibility of reversals, and the likelihood that MAROs will not always be perceived in the same way in the United States, in the area of operations, and internationally. Given the clear-eyed view with which the authors have considered much of what would be required for humanitarian military missions, the weakness of the proposed handbook is essentially a failure to extend that critical capacity to a few key omissions and assumptions. These include the historical lack of enthusiasm for US military cooperation with the United Nations and other forces and peacekeeping or peace enforcement operations in general, a lack of adequate consideration for exactly how coalition forces might work together, insufficient concern over the ability to collect accurate intelligence and appropriately analyze that intelligence, and a perhaps unwarranted assumption that the US military, powerful though it may be, will always be successful on the battlefield.

\section{MARO and R2P}

In establishing the need for mass atrocity response planning and operations, the authors argue that MARO is closely related to but qualitatively different from R2P in a few key respects: $M A R O$ 's focus on the use of military force after the killing has begun rather than a constellation of diplomatic, economic, and other approaches referred to in R2P doctrine; an emphasis on preparing the US military specifically for MAROs rather than advocating, as the R2P does, that international military force should be deployed to counter atrocity crimes; and an "agnostic" view of the politics of how the US military would come to engage in a MARO rather than R2P's requirement that the use of military force be sanctioned by the United Nations Security Council. ${ }^{1}$ In short, MARO concentrates, as the authors tell us, on "how" to use military force, rather than on "whether."

Despite the evident differences between $M A R O$ and R2P, the expressed need for MARO planning by the US or other military forces seems to be at the very least indirectly influenced by the central principles of R2P. In defining the international community's responsibility to protect, the International Commission on International and State Sovereignty (ICISS) argued that while the responsibility to protect a given population lies "first and foremost" with the state which controls that population, there is a "residual responsibility" shared by all states in the international system. ${ }^{2}$ This residual responsibility, the ICISS continues, is triggered "when a particular state is clearly either unwilling or unable to fulfill its responsibility to protect or is itself the actual perpetrator of crimes or atrocities, or where people living outside a particular state are directly threatened by actions taking place there." Further, "the substance of the responsibility to protect is the provision of life-supporting protection and assistance to populations at risk." The responsibility to protect is said to be composed of three separate sub responsibilities: to react, prevent, and rebuild. The forward to MARO begins by noting that the "MARO project seeks to enable the United States and the international community to stop genocide and mass atrocity" and that it is based on the "insight that the failure to act in the face of mass killings of civilians is not simply a function of political will or legal authority" but also a "lack of thinking about how military force might respond" (5). Although no reference is made in this passage directly to R2P's constituent responsibilities, we can see oblique references to the responsibility to react in the suggestion that MARO planning would enable the United States and others to stop genocide and that lack of such planning has led to the failure to act in the past. Sewall, Raymond, and Chin 
continue by suggesting that not only does planning for MAROs allow for more effective military responses, but the ability to use military force effectively to stop atrocities may "help strengthen deterrence of would be perpetrators" (i.e., the responsibility to prevent [5]). In a later section in which the authors outline different kinds of MARO missions, the most interventionist scenario ends with proposals for the restoration of security and proper local governance (i.e., the responsibility to rebuild [70-87]).

Similarly, although MARO does not overtly refer to the six principles governing military intervention set out in $\mathrm{R} 2 \mathrm{P}$ (right authority, just cause, right intention, last resort, proportional means, and reasonable prospect), ${ }^{3}$ there are hints that MAROs should be designed to conform to at least some of these principles. For example, that the purpose of a MARO is to stop mass atrocities once the killing has begun or is imminent suggests just cause to safeguard or save populations that are either at risk or already the targets of mass atrocities. The insistence that MAROs are distinct from other kinds of military operations because they are strictly for the purpose of assisting targeted populations sounds a lot like right intention, despite the very real possibility that perpetrators of atrocity crimes and some elements of the international community will see MAROs, particularly if conducted by the US military, as illegitimate violations of another state's sovereignty.

Finally, even though MARO's authors claim that MAROs do not involve nonmilitary methods of preventing and stopping mass atrocities, the handbook nonetheless devotes a section to Flexible Deterrent Options (FDOs). The concentration is, appropriately, on a sliding scale of military FDOs from heightening the alert status of designated units to increasing surveillance activity and prepositioning military assets in the region, and to establishing no-fly zones, for example (67-68). But there is an acknowledgment that military commanders will need to be mindful of how military FDOs will affect and be affected by non-military diplomatic, informational, and economic FDOs pursued by civilian leaders and departments and the possibility that military FDOs will be used to support non-military FDOs (69). Although not explicit, the notion that non-military FDOs will likely precede military intervention or may require the support of the military in order to, for example, gather intelligence or position forces to make diplomatic threats of the use of force credible seems to suggest a tacit acknowledgement that any MARO will follow R2P's injunction that the use of military force be a last resort. In short, this and the above examples would seem to suggest that although proposed MARO planning does not follow the letter of all of R2P doctrine, it certainly follows the spirit of central aspects of it.

\section{MARO's Strength: Acknowledging Complexity}

The great strength of the handbook is the authors' refusal to take the easy route and suggest one simplistic plan for circumstances that are anything but simple in the real world. Instead, the handbook acknowledges throughout that mass atrocity situations, and by extension MARO operations, are highly complex. The handbook, for example, refers at various points to the different kinds of actors involved directly or indirectly in mass atrocity situations and possible MAROs: perpetrators who may be state or non-state actors, victims, interveners such as external military forces as well as UN peacekeepers or regular and irregular forces from neighboring countries, and "other actors" such as uninvolved populations in the country, neighboring populations or leaders, regional organizations (e.g., AU, NATO), UN agencies or political missions, international and local non-governmental organizations (NGOs), and the media-all of these can be categorized as bystanders, "negative influences," or 
"positive influences" depending on their actions (44-49). Although one can argue that regional organizations, UN missions, and NGOs can just as easily be conceptualized as interveners, albeit of a non-military variety, MARO nonetheless acknowledges the sheer variety of potential actors involved and, more importantly, it does not assume a static role for these actors. The authors note, for example, that as atrocities and MAROs evolve, victims may become perpetrators, local or regional bystanders-be they civilian or military-may also become perpetrators, and perpetrators may not be deterred by initial non-military or military FDOs and instead calculate that they must move quickly to strike down their targets before it is too late.

Similarly, the handbook recognizes that all of these actors have their own specific, often competing, interests that can shift over time. Importantly, the authors note that competing interests are not only a characteristic of the relationship between adversaries, such as perpetrators and interveners, but also of relationships between those who are on the "same side," as in the case of intervening military forces and NGOs as the latter usually seek to maintain distance from the former while sharing the goal of assisting the victims. Further, MARO also identifies the ways in which actors perceive their own actions as well as the ways in which their actions are perceived by other local actors and members of the international community as variable and often at odds with each other. Sewall, Raymond, and Chin repeatedly caution, for instance, that although the US military and the United States in general may perceive a MARO to be strictly for humanitarian purposes, the use of military force against the perpetrators of atrocity crimes will be seen as adversarial by the perpetrators themselves and possibly as imperialistic by regional and international observers. While the authors do not suggest concrete ways of dealing with such perceptual disconnects, it is crucial that the United States and other coalition forces are aware of the possible problem of differing, often negative perceptions, in order to anticipate how their actions will be received by various audiences and how this reception may affect MARO missions.

The authors also acknowledge complexity by formulating not one but several different MARO scenarios, all of which are identified as possible responses to different kinds of mass atrocity situations and/or force levels available for such operations. Scenarios range from relatively minimal interventions that involve using military assets such as ships, aircraft, and long range surveillance mostly from outside of the country to those that involve the setting up of safe zones in order to safeguard target populations that are geographically concentrated, major operations in which the country is saturated with intervening forces in several locations when the target group is dispersed, and to operations that aim for the complete military defeat of the perpetrators. The problems cited above of competing and changing roles, interpretations, and perceptions are written into each scenario. The relative advantages and disadvantages, the latter of which frequently hinge on what could possibly go wrong, are also addressed, albeit in a rather brief fashion.

\section{MARO's Weaknesses: Forgetting Complexity}

Given the evident ability of the authors of $M A R O$ to consider how convoluted mass atrocity situations and MAROs are likely to be, it is surprising that some of the most vexing problems that have led the United States and other states to reject MARO-like military interventions in the past are missing from the proposed plan. Admittedly, not all of the missing complexities are of a directly military nature, but they are highly relevant to the process of conceptualizing possible MARO missions 
since these missing complexities will directly shape political commitments to MAROs, the availability of resources, and the willingness of the US military to take on and the ability to succeed at such missions.

The first missing element of complexity is a more detailed and explicit recognition that, on the one hand, the US government and military have been reluctant to work closely with the United Nations and forces operating under UN command and, on the other hand, that US forces are unlikely to conduct a MARO unilaterally. Although the US military has operated alongside the United Nations and other coalition forces for humanitarian purposes in the past, especially NATO, MARO's authors correctly note the reluctance of American forces to engage in multilateral operations. The authors use this reluctance as a justification for proposing a manual that would be used by the US armed forces regardless of whether a MARO operation is sanctioned by the United Nations Security Council and/or is carried out alongside $\mathrm{UN}$ or other international forces. But if the past is any predictor of the future, there is little evidence that the United States will be willing to conduct such a mission alone in response to a mass atrocity situation. Since the end of the Cold War, MARO-like humanitarian military interventions have been multinational coalition operations, usually under some sort of UN mandate. Bosnia, Kosovo, and Somalia for better or worse are all examples. As such, $M A R O$ should have spent or, to put it more constructively, future iterations of the handbook should spend, much more time setting out exactly how US forces will work alongside international forces.

A second and closely related forgotten complexity is the issue of military culture. The US military sees itself as an institution tasked with protecting and projecting American military power by preparing for traditional warfare and, since the September 2001 attacks, counter-terrorism operations. For $M A R O$ to have any currency inside the US military, a parallel process of changing military culture to accept MARO missions as a legitimate use of personnel, military assets, planning, and training will be necessary. Without this kind of shift in military culture starting from senior commanders and spreading down the ranks, MAROs will likely be seen as second class operations unworthy of the world's most powerful military and, as a result, American armed forces will fail to properly prepare for them. Further, resistance to MAROs may lead senior commanders to advocate against such missions at the political level. It is of course a hallmark of civil-military relations in all democracies that civilian leaders decide when, where, and why to deploy military forces, but it would be naïve to think that civilian leaders do not on occasion face objections from senior military commanders to missions that they would rather not carry out or objections in favor of missions that senior commanders would rather pursue. One way of gaining acceptance of MARO missions and ensuring that the military can successfully carry out MAROs might be to add a section on training. This could include the nuts and bolts of instructing officers and NCOs on what is expected of them during MARO missions as well as an emphasis on the importance of these kinds of missions. Concerning the latter the manual could underline the moral worth of humanitarian missions to stop atrocities while also making a case for the practical ways in which MARO missions enhance American and international peace and security. The recently released Will to Intervene Project, developed by the Montreal Institute of Genocide and Human Rights Studies (MIGS), could serve as a template for the realpolitik reasons for legitimizing MARO missions.

Third, MARO seems to assume that intelligence gathering and analysis will be a relatively straightforward process. The authors rightfully integrate the need for effective intelligence gathering and analysis into MARO planning and missions, 
specifically the role intelligence plays in discerning the intentions and concrete plans of actual or would-be perpetrators. The handbook fails, however, to address the very real possibility of not obtaining timely and accurate intelligence in some circumstances or the possibility that the US military and the Pentagon may misinterpret the intelligence collected. If genocide or another atrocity breaks out in parts of the world where the United States and other major powers have little strategic interest, the capacity to directly collect timely and accurate intelligence will be diminished from the start. In such circumstances intelligence may have to come from other second-hand sources and, as a result, it may be less reliable intelligence or intelligence that is unintentionally or deliberately misleading. Although local and international media reports may be an alternative source of information, the domestic media can become a weapon in the hands of abusive states (which in itself may, of course, turn out to be a highly accurate source of perpetrator intentions) while the international media at times approach news stories from particular regions of the world with pre-existing and often inaccurate narratives in mind (e.g., that Africans habitually engage in "tribal violence").

Regardless of where the intelligence comes from or how accurate it is, there is no guarantee that civilian and military agencies tasked with analyzing intelligence will be able to correctly assess the true nature of an atrocity situation. One need only think of the inability of most Western states to comprehend until it was too late that the killings in Rwanda were not spasms of tribal violence or the collateral effects of the civil war or that Iraq's Saddam Hussein regime did not in fact have weapons of mass destruction. Sewall, Raymond, and Chin tell us that MARO planning must be based in part on a clear understanding not only of perpetrator planning and intentions but also of the historical, economic, political, and strategic context within which atrocities are perpetrated. This makes imminent sense, but generating this level of understanding under what at times may be very pressing time constraints is likely to be a weighty and vexing task. Scholars have spent years trying to figure out the dynamics underpinning mass atrocity situations with varying degrees of success and agreement. To be able to meet the challenge of effective intelligence analysis, relevant civilian and military agencies will need to acquire considerable analytical expertise in genocide studies and other atrocity crimes.

Finally, there is the perhaps overly optimistic unspoken assumption that the US military, once committed to some sort of combat operations as part of a MARO, will succeed on the battlefield. The US army is the largest one in the world and it has gained, complements of extended engagements in Iraq and Afghanistan, some serious recent combat experience. These two theaters of war show that although the American military has little difficulty prevailing in traditional set-piece combat operations, it has faced problems despite its overwhelming capabilities in irregular and counterinsurgency settings. It is these latter kinds of operations that will likely characterize most MARO missions. MARO's authors do, to be fair, acknowledge in different MARO scenarios the possibility of set-backs and reversals, but this possibility is attributed to other actors and not to the US military itself. A frank acknowledgement of the possibility of failure on the battlefield is crucial for understanding what might go wrong with the application of force itself, how to avoid such problems, or at least how to compensate for problems or make successful mid-course corrections.

In sum, the proposed handbook is a good first step on the road to figuring out how military force, if it is needed, can be used effectively to stop the perpetration of atrocity crimes against vulnerable populations. Grounded in the R2P principle of the responsibility to react, $M A R O$ has tried to confront much of the complexities that 
surround atrocity situations and possible military responses to them. To move the conversation forward we need to confront the equally complex problems of finding ways in which the US and coalition forces, such as the United Nations or NATO, would work together on the ground in MARO missions; the ways in which to get American and other national militaries to take MARO missions seriously; the ways in which to collect and analyze accurate and timely intelligence; and the ways in which to anticipate from an operational point of view, what might go wrong on the battlefield and how to fix it. Sewall, Raymond, and Chin should be commended for their initiative, creativity, and evident hard work in conceptualizing MARO. The conversation they have started should be continued inside and outside military circles and is of the highest importance if the major states in the international system ever hope to live up to their responsibility to protect those who need protection.

\section{Notes}

1. Sarah Sewall, Dwight Raymond, and Sally Chin, MARO: Mass Atrocity Response Operations; A Military Planning Handbook (Cambridge, MA: Harvard Kennedy School / Carr Centre for Human Rights Policy, 2010), 12-13. Subsequent references appear parenthetically in the text.

2. Gareth Evans and Mohamed Sahnoun, Co-Chairs, The Responsibility to Protect: The Report of the International Commission on Intervention and State Sovereignty, (Ottawa, ON: International Development Research Centre, December 2001), 17.

3. Ibid., 32-37. 